Int. J. Dev. Biol. 60: 209-219 (2016)

doi: $10.1387 / \mathrm{ijdb} .160077 \mathrm{dp}$

\title{
A sea urchin cell-free system to study male pronuclear assembly and activation
}

\author{
DOMINIC POCCIA* \\ Department of Biology, Amherst College, Amherst, MA, USA
}

\begin{abstract}
Typically sperm nuclei are genetically inert and contain extremely compacted chromatin. Following fertilization, the first steps in their conversion to somatic nuclei (male pronuclei) which will support further development involve chromatin decondensation and the formation of a new nuclear envelope. We have studied the reactivation of sea urchin sperm nuclei in a cell-free system derived from homogenates of activated sea urchin egg cytoplasm. The cell-free system has provided several novel insights including requirements for sperm-specific histone phosphorylation on $\mathrm{N}$ - and C-terminal extensions and disassembly of the sperm nuclear lamina for decondensation, the utilization of remnant regions of the sperm nuclear envelope to direct polarized binding and fusion of egg membranes to form the new nuclear envelope, and a role for phosphoinositide metabolism in initiation of membrane fusion through binding of a minor membrane fraction enriched in Ptdlns $(4,5) P_{2}$, PLC $\gamma$ and SFK1 which locally produces a fusigenic lipid, diacylglycerol.
\end{abstract}

KEY WORDS: male pronucleus, chromatin, nuclear envelope, membrane fusion, sea urchin

\section{Introduction}

My interest in the transformation of the inactive sperm nucleus into a male pronucleus following fertilization began as a graduate student in 1970 working on sea urchin early embryo chromatin. I enrolled in the Marine Biological Laboratory's summer Embryology course at Woods Hole where I attended a lecture by Frank Longo who presented beautiful electron micrographs from his recent graduate work on the morphological transformations of the sea urchin sperm nucleus that immediately follow fertilization (Longo and Anderson, 1968). Longo showed that the sperm nuclear membrane was rapidly removed as the nucleus penetrated egg cytoplasm and that the compact conical chromatin mass then progressively decondensed from the outside in while becoming associated with numerous membrane vesicles at its surface. Those vesicles appeared to fuse together to create the new nuclear envelope of the male pronucleus.

Sea urchin sperm chromatin is as densely packed as any nucleosomal chromatin structure can be, about the same as mitotic chromosomes (Green and Poccia, 1985; Poccia and Collas, 1996). It has the largest ever reported average length of linker DNA (DNA between adjacent nucleosomes that preferentially binds $\mathrm{H} 1$ histone) (Savic et al., 1981). The very densely packed sperm chromatin has to be quickly decondensed in order to re-activate replication and transcription and permit rapid embryonic cell cycles. In contrast to most organisms, early gene expression in the sea urchin begins within the first cell cycle (Poccia et al., 1984; Poccia, 1986).

We knew that sea urchin chromatin contained sperm-specific (Sp) histones of the $\mathrm{H} 1$ and $\mathrm{H} 2 \mathrm{~B}$ classes with highly basic $\mathrm{N}$ terminal extensions, a very unusual situation since histones are among the most highly evolutionarily conserved proteins known. I wondered if it were possible to study post-translational modifications and replacements of the Sp histone variants during the period of chromatin decondensation to learn how they might contribute to activation. However, since the ratio of cytoplasm to nucleus in a single fertilized egg is extremely high and large quantities of somatic histones are stored in the egg cytoplasm it was impossible to isolate sufficiently purified nuclei to analyze their histones. We turned to polyspermically fertilized eggs to solve this problem and found that phosphorylation of the two sperm-specific histones on their $\mathrm{N}$-termini was very rapid in the egg, preceding decondensation (Green and Poccia, 1985).

Although we had learned a great deal from the polyspermic egg system, I had thought about how an in vitro system might allow us to manipulate the nuclei to describe in greater detail the relationship of decondensation and histone phosphorylation. However

Abbreviations used in this paper: DAG, diacylglycerol; LS, lipophilic structure; MV, membrane vesicle; NE, nuclear envelope; NER, nuclear envelope remnants.

\footnotetext{
*Address correspondence to: Dominic Poccia, Dept. Biology, Amherst College, Amherst, MA 01002, USA. Tel: 413-542-2198. Fax: 413-542-7955.

E-mail: dlpoccia@amherst.edu
}

Accepted: 23 March 2016

ISSN: Online 1696-3547, Print 0214-6282 

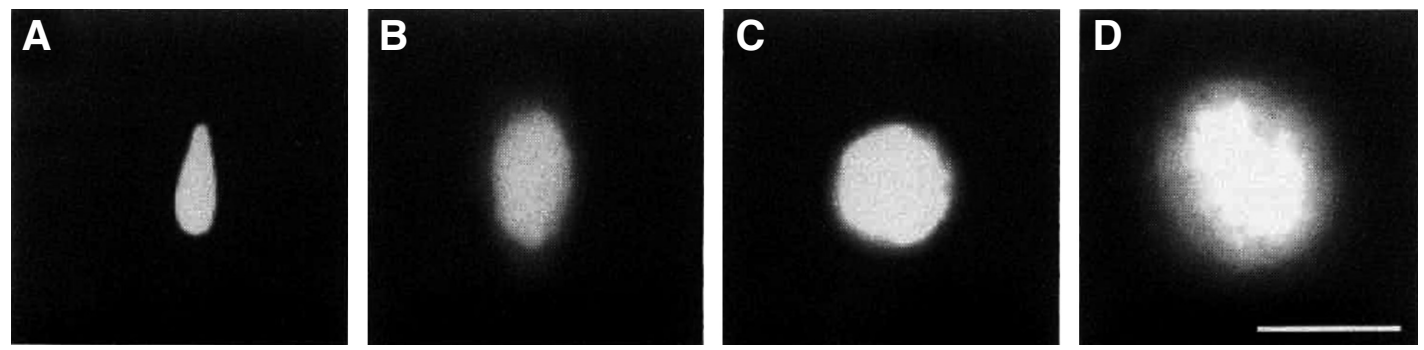

Fig. 1. Sea urchin sperm chromatin decondensation in vitro. Demembranated sperm nuclei incubated in egg extracts containing an ATP-generating system. (A) Input nucleus. (B) Ovoid partially decondensed nucleus. (C) Spheroid 4 um diameter decondensed nucleus. (D) Swollen 8 um diameter nucleus. Stained with Hoechst 33342. Bar, 10 um. From Collas and Poccia (1998a).

it was not until 1983 at a Gordon Conference on Fertilization at Colby College that I met Manfred Lohka who explained how, working in Yokio Masui's lab in Toronto, he had developed a cell-free system from frog eggs that supported decondensation and mitotic condensation of exogenous sperm chromatin. Frog egg extracts had already been used with exogenous DNA to study replication enzymology (Gandini Attardi et al., 1976; Mattoccia et al., 1976). For us, however, the importance of Lohka and Masui's system was that it worked on sperm nuclei and appeared to lead to well-regulated events of the cell cycle with all the advantages of making possible biochemical manipulations of various stages of the cycle (Lohka and Masui, 1983a; Lohka and Masui, 1983b; Lohka and Masui, 1984a; Lohka and Masui, 1984b; Vigers and Lohka, 1991). They went on to show that their system also supported nuclear envelope formation and it was subsequently adopted by many labs to study replication, cell cycling, spindle formation and nuclear transport.

I wanted to develop a similar system derived from sea urchin eggs to look at histone modifications, but because we were still working on polyspermic eggs and microinjecting sperm nuclei into live oocytes, I tucked my conversation with Fred back into longterm memory and we made only minimal attempts to develop a cell-free system from sea urchins. But after a decade had passed, we decided by chance to return to the problem.

In 1993, an undergraduate student of mine, Lisa Cameron, was having trouble microinjecting sperm nuclei into eggs so I suggested halfway through her thesis that she take a break and try to make a functional sea urchin egg extract. The first results using a medium similar to Lohka's but supplemented with non-ionic compounds to simulate the tonicity of the sea urchin cytoplasm were disappointing. But it quickly occurred to us that maybe we were lacking energy for the transformations and upon adding ATP we observed the first decondensation of exogenous sea urchin sperm nuclei (Cameron and Poccia, 1994). Presumably Lohka's extracts had sufficient mitochondria to provide ATP and ours did not. Our observations led us to devote much of the next 20 years to studying the effects of the cell-free system on decondensation, histone phosphorylation, and nuclear envelope formation, relating whenever feasible in vitro results with in vivo observations.

For this special issue on cell-free systems, I will summarize our major findings which have not been previously gathered into a single presentation and indicate some advantages and limitations of the existing system and certain issues remaining to be investigated. More detailed summaries of material contained herein may be found in several reviews (Poccia, 1986; Poccia, 1989; Poccia and Green, 1992; Green et al., 1995; Poccia and Collas, 1996; Poccia and Collas, 1997; Collas and Poccia, 1998b; Collas and Poccia,
2000; Poccia et al., 2002; Byrne et al., 2009; Byrne et al., 2009; Larijani and Poccia, 2009; Larijani and Poccia, 2012; Larijani et al., 2014). Details of methods and procedures may be found in several methods papers (Poccia and Green, 1986; Collas and Poccia, 1998a; Byrne et al., 2009; Garnier-Lhomme, Dufourc, et al., 2009).

\section{Characteristics of the cell-free system}

At 10-15 min post-fertilization, activated sea urchin eggs are homogenized with a hypodermic syringe in a buffer containing $\mathrm{NaCl}, \mathrm{MgCl}_{2}$, glycine, glycerol, DTT and Hepes, pH 7.2. A 10,000 $\mathrm{g}$ supernatant is prepared. The small overlying yolky layer is removed after which the extract is used directly or quick frozen for future use (Cameron and Poccia, 1994; Collas and Poccia, 1998a; Byrne et al., 2009).

Sperm nuclei are prepared and demembranated by sonication in a buffer containing Triton X-100 followed by low speed centrifugation. The assembly system is prepared by addition of nuclei and an ATP-generating system to the extract. Under these conditions, the dense conical sperm nuclei decondense progressively from the outside-in as they do in vivo forming spherical masses of 4 $\mu \mathrm{m}$ diameter (Fig. 1).

The rate of decondensation depends on the concentration and $\mathrm{pH}$ of the extract which are optimal at $7 \mathrm{mg} / \mathrm{ml}$ protein and $\mathrm{pH}$ 8. Decondensation is minimal in unfertilized egg extracts unless the $\mathrm{pH}$ is raised, does not require $\mathrm{Ca}^{++}$, is inhibited by protein
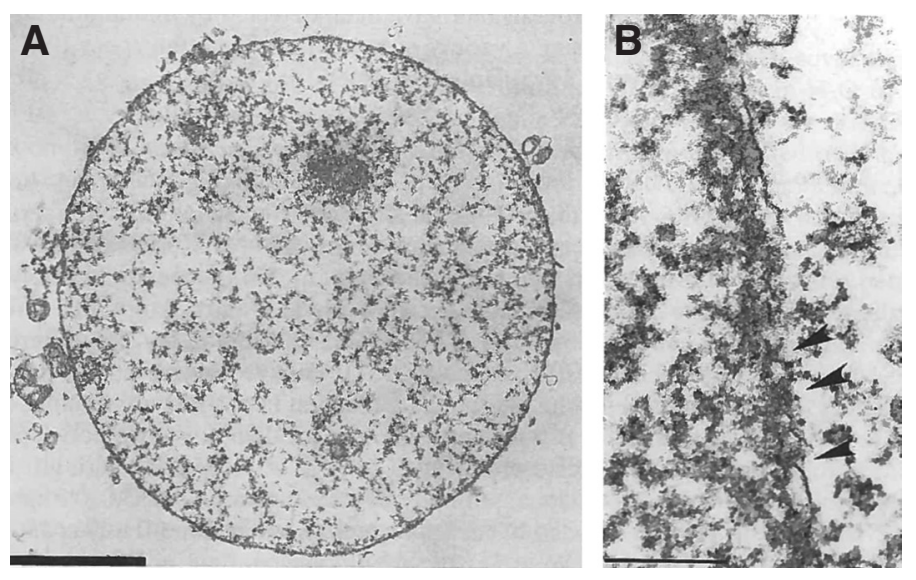

Fig. 2. Electron micrograph of swollen nuclei formed in vitro. (A) The nucleus is completely enclosed in a new nuclear envelope. (B) Nuclear pores are visible interrupting the two nuclear membranes (arrowheads). Bar, $0.1 \mu \mathrm{m}$. From Collas and Poccia (1998a). 
kinase inhibitors at concentrations effective in vivo and requires ATP hydrolysis. Decondensation is not accompanied by histone degradation (Cameron and Poccia, 1994; Green et al., 1985). In its requirements, decondensation behavior in vitro closely mimics that in vivo (Poccia et al., 1978; Luttmer and Longo, 1987; Cothren and Poccia, 1993). The system as constituted however does not cycle or even proceed to mitosis, although we have not tried to optimize it for those purposes.

Addition of GTP promotes nuclear envelope formation and swelling of the decondensed nuclei (Fig. 1, 2). Decondensation and swelling are separate phenomena. The former is membrane independent and the latter requires formation of a nuclear envelope (Collas and Poccia, 1995a). If membranes are removed from the egg extract by a $150,000 \mathrm{~g}$ centrifugation, exogenous sperm nuclei decondense only to a diameter $\sim 4 \mu \mathrm{m}$. Swelling to $\sim 7 \mu \mathrm{m}$ requires initial formation of a nuclear envelope from membranes but once it forms it is independent of additional membranes. Swelling requires ATP hydrolysis, $\mathrm{Ca}^{++}$and cytosolic factors sensitive to heat and $\mathrm{N}$-ethylmaleimide inhibition (which blocks NSF-mediated membrane fusion) and resembles in vivo swelling. Nuclear swelling requirements are consistent with protein import mechanisms and similar to those of the amphibian cell-free system (Lohka and Masui, 1984b).

Thus the cell-free system supports the steps that result in the formation of the male pronucleus: chromatin decondensation, nuclear envelope formation, protein import and nuclear swelling. Conditions for cycling remain to be established.

\section{Phosphorylation of sperm-specific histones and sperm lamin $B$ are required for decondensation in vitro}

On the basis of in vivolabeling experiments with our polyspermic system and many studies on gametogenesis and mitosis progression that suggested that histone phosphorylation/dephosphorylation events accompany gross changes in chromatin condensation (Green and Poccia, 1985; Simpson and Poccia, 1987; Green and Poccia, 1988; Roberge Th'ng et al., 1990; Oliva and Dixon, 1991; Green et al., 1993; Green et al., 1994), we postulated that phos- phorylation of the sperm-specific histones $\mathrm{SpH} 1$ and $\mathrm{SpH} 2 \mathrm{~B}$ would be required to alter the affinities of their highly basic $\mathrm{N}$-terminal extensions (and the Sp H1 C-terminal extension) with the negatively charged backbone of chromatin linker DNA to permit postfertilization chromatin decondensation (Green and Poccia, 1988).

During spermatogenesis $\mathrm{Sp}$ histones are actively phosphorylated within these extensions on multiple "SPKK" motifs but are not found phosphorylated in mature sperm (Poccia et al., 1987). We suggested that phosphorylation during spermatogenesis allowed correct positioning and adjustment to the long linker DNA which was then "locked" in place by dephosphorylation to stabilize the mature sperm chromatin. It was subsequently demonstrated by comparison of sperm and spermatid chromatin physical properties that phosphorylation of SPKK sequences in $\mathrm{SpH} 1$ and $\mathrm{SpH} 2 \mathrm{~B}$ histones indeed weakens linker interaction (Hill et al., 1991) and that in addition to linker histone $\mathrm{H} 1$, the $\mathrm{N}$-terminal region of the core histone SpH2B binds to linker DNA (Hill and Thomas, 1990). However it was difficult to effectively manipulate histone phosphorylation transitions during spermiogenesis progression.

If dephosphorylation of the Sp histones stabilized the condensed state of sperm chromatin, it would be expected to be rapidly reversed in the egg. Studies of nuclei isolated from polyspermically fertilized eggs confirmed this prediction (Green and Poccia, 1985). Analysis of male pronuclear histones from embryo extracts pre-loaded with radioactive phosphate identified the two $\mathrm{Sp}$ histone variants as the major histone targets for phosphorylation, indicating that regarding initial histone modification events, the extracts behaved like cytoplasm in vivo (Green et al., 1995). Peptide analysis showed that phosphorylation occurred in the $\mathrm{N}$ - and $\mathrm{C}$-terminal extensions of $\mathrm{SpH} 1$ and the $\mathrm{N}$-terminal region of $\mathrm{SpH} 2 \mathrm{~B}$ (Fig. 3).

The phosphorylation of $\mathrm{Sp}$ histones turned out to be necessary but not sufficient to decondense sperm nuclei in vitro, since inhibition with the non-specific kinase inhibitor 6-DMAP blocked decondensation while permitting $\mathrm{Sp}$ histone phosphorylation (Poccia et al., 1990). This result contradicted the idea that histone dephosphorylation alone controlled decondensation.

We then noted that Sp-phosphorylated sperm nuclei retaining their lamina did not decondense in vitro. Removal of the lamina
Fig. 3. Phosphorylation of sperm-specific histones SpH1 and SpH2B by egg cytosol. Sperm histones incubated in egg cytosol containing radioactive $\left[\gamma^{-32} \mathrm{P}\right]$ ATP are phosphorylated on their unique $\mathrm{N}$-terminal regions which contain SPKK motifs. (A) SpH1 cleaved with $\mathrm{N}$-bromosuccinimide. (B) $\mathrm{SpH} 2 \mathrm{~B}$ cleaved with cyanogen bromide. SDS gels were stained with either Coomassie Blue or Ag-stain and autoradiographed. The sites of SPKK motifs and cleavage sites are indicated diagrammatically to the right. Asterisks indicate known phosphorylation sites. Black and white pairs of bars indicate SPKK tetrapeptides. From Stephens et al., (2002). (C) In vivo sites of phosphorylation. SpH2B is labelled exclusively in its $\mathrm{N}$-terminal peptide; $\mathrm{SpH} 1$ is labelled on both Nand C-terminal peptides. Cleaved with $\mathrm{CnBr}$ and NBS respectively. From Green et al., (1995).
A

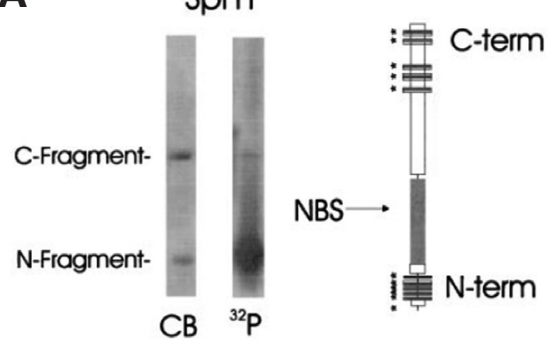

B

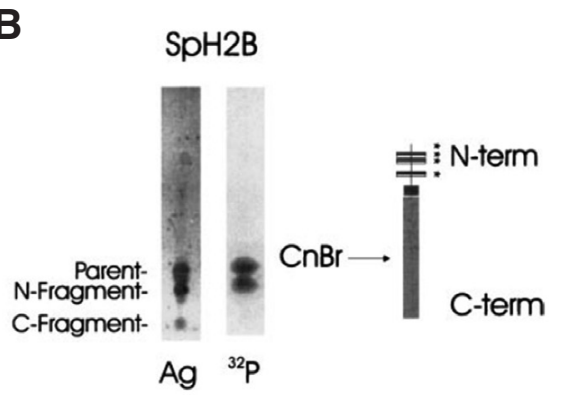

C
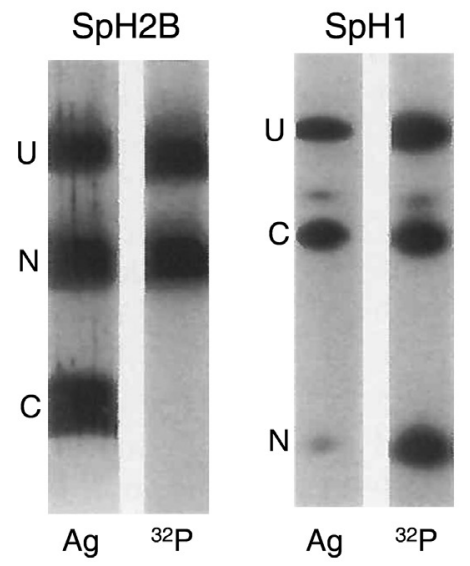


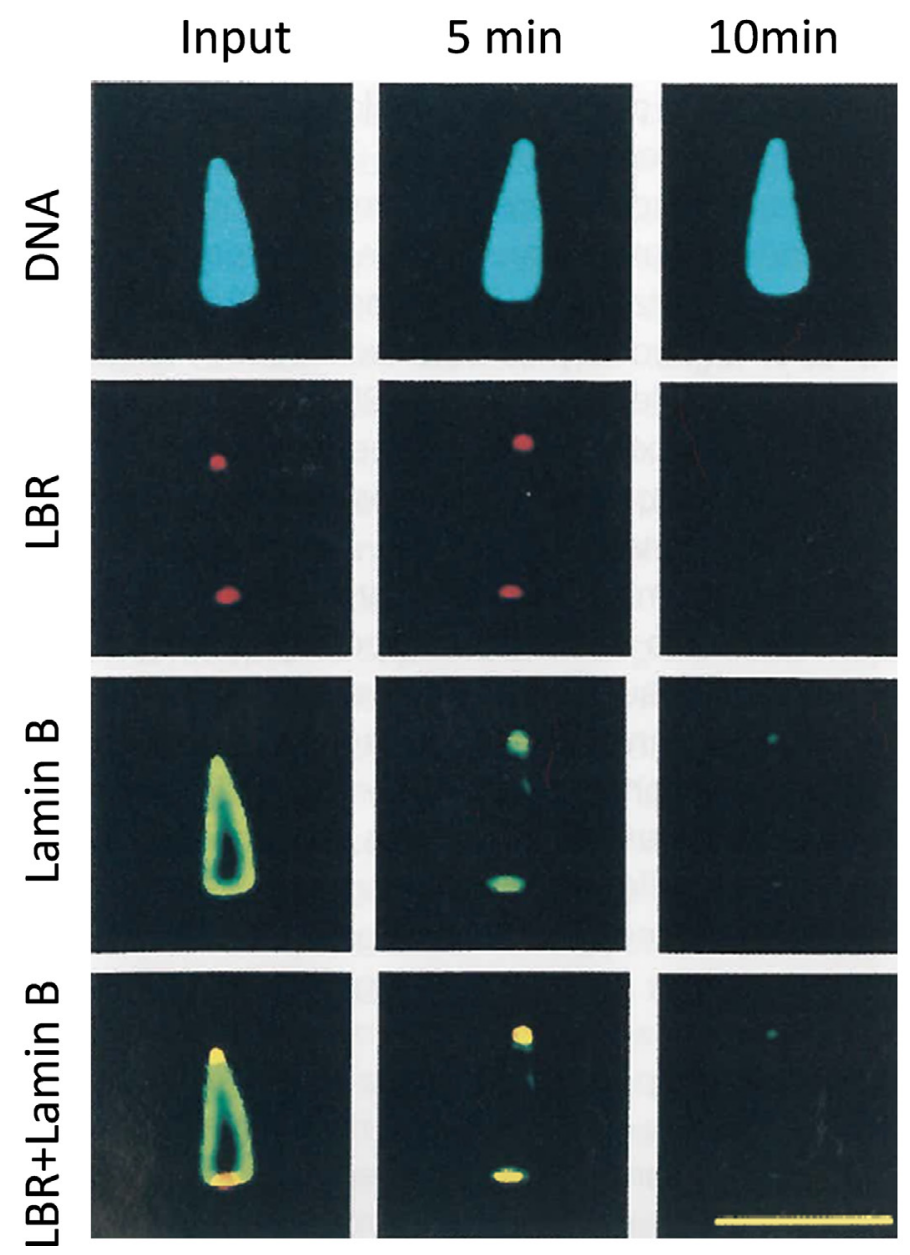

Fig. 4. Removal of lamin B and lamin B receptor (LBR) from sperm nuclei by egg extracts. DNA stained with Hoechst 33342, LBR with anti-human $L B R$ antibody, lamin $B$ with anti-sea urchin lamin $B$ antibody. Time of incubation indicated. Bar, 5 um. From Poccia and Collas (1997).

depends on protein kinase C (PKC) phosphorylation of lamin B which permits its solubilization (Collas et al., 1997; Poccia and Collas, 1997). In vitro lamin phosphorylation and removal begins within 1-2 minutes of incubation in egg cytosol and precedes decondensation (Fig. 4). It depends on $\mathrm{Ca}^{++}$and is specifically inhibited by a PKC-specific chemical inhibitor, a PKC pseudosubstrate inhibitor peptide, and a PKC substrate peptide. It is also prevented by immunodepletion of PKC from cytosol and restored by addition of exogenous purified mammalian PKC which gives the same phosphopeptide mapping pattern as the extract itself.
Based on these observations, we defined the minimal requirements for decondensation in vitro both in the cell-free system and also in the complete absence of cytosol or membranes (Stephens et al., 2002). Decondensation could be achieved by a combination of two exogenous kinases: a cdc2 kinase capable of phosphorylating the SPKK sequences of the Sp histones and a PKC capable of phosphorylating lamins. Thus we suggested that once most of the sperm nuclear membrane is disassembled, chromatin decondensation requires phosphorylation of the terminal basic extensions of $\mathrm{SpH} 1$ and $\mathrm{SpH} 2 \mathrm{~B}$ to weaken the electrostatic interactions with the linker DNA backbone and phosphorylation of sperm lamins to allow lamina disassembly. These conditions permit the chromatin to decondense to a more energetically favorable configuration that minimizes electrostatic repulsion of DNA phosphate charge.

The identity of the endogenous Sp histone kinases remains unknown but it is probably similar in specificity to cdc2. It was recently reported that a protein kinase $\mathrm{C}$ activator facilitated male pronuclear development in pig oocytes injected with sperm (Nakai et al., 2015) suggesting that lamina removal by protein kinase C might be a conserved condition for male pronuclear progression at least in the deuterostomes.

In vivo, phosphorylation of the Sp histones and chromatin decondensation would normally be followed by Sp histone removal and their replacement (presumably facilitated by exchange factors) with CS histone variants stored in the egg cytoplasm during oogenesis, (Cohen H., Newrock,K., M., and Zweidler, 1975; Oliver et al., 2002). Unfortunately, only a minimal amount of CSH1 or other variants stored in the egg was incorporated into the chromatin in vitro and $\mathrm{Sp}$ histone removal was not efficient.

Therefore extensive additional remodeling of the chromatin did not take place in the cell-free system once the male pronucleus was formed. This likely prevented further cell cycle progression.

\section{Several membrane populations and egg lamin B contribute to new nuclear envelope formation in the cell-free system}

Once phosphorylation of Sp histones, removal of sperm nuclear membranes and lamina and decondensation of sperm nuclei are accomplished, the male pronucleus can be formed. In vivo this begins with the assembly of a new nuclear envelope, an event followed by migration to and fusion with the female pronucleus creating the zygote nucleus (Longo and Anderson, 1968; Poccia and Collas, 1996).

Nuclear envelope formation in vitro was more complex than anticipated, involving the participation of several different membrane populations to enclose the chromatin and subsequent rather than concomitant lamina formation. Analysis of nuclear envelope

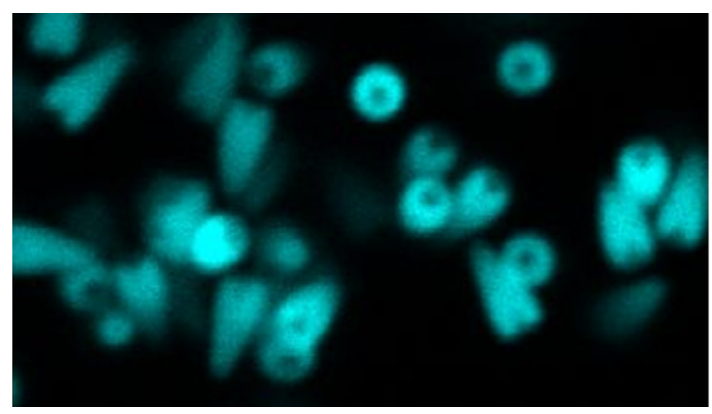

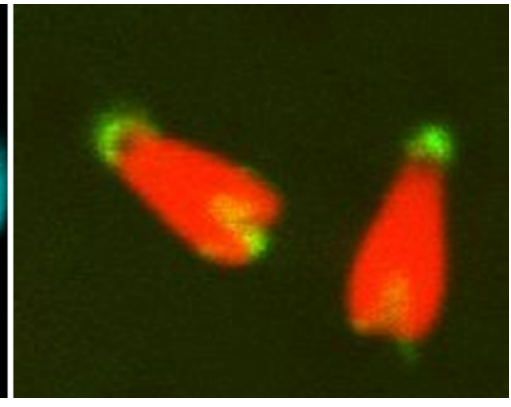

Fig. 5. Fluorescence images of sea urchin sperm nuclei demembranated with $0.1 \%$ Triton $\mathrm{X}-100$. DNA fluorescently stained blue with Hoechst 33342. DNA stained red with propidium iodide and membranes of lipophilic structures stained green with diOC . 

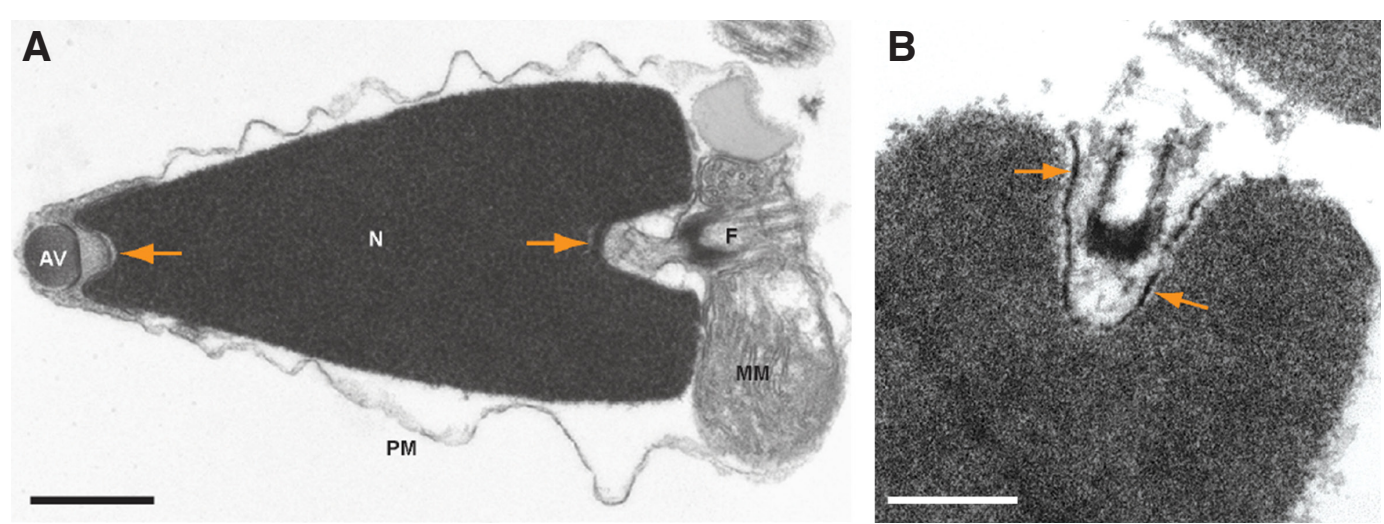

Fig. 6. Electron micrographs of sea urchin sperm head and isolated sperm nucleus treated with $0.1 \%$ Triton X-100. (A) The plasma membrane (PM) is somewhat swollen in this preparation. Arrows point to the acrosomal and centriolar fossae. AV, acrosomal vesicle. $N$, nucleus. MM, midpiece mitochondrion. (B) Base of demembranated condensed nucleus. Arrows point to regions of lipophilic structures or nuclear envelope remnants. Basal body remains embedded in its fossa. Tail axoneme and mitochondrion have been sheared away. From Garnier-Lhomme, Byrne et al., (2009).

formation also led to unforeseen roles for phosphoinositides and diacylglycerol in the membrane fusion process and the realization that fusion was polarized, beginning at the two sites of the remnants of the sperm nuclear membrane which are not disassembled in vivo following fertilization (Longo and Anderson, 1968).

\section{Sperm lipophilic structures (LS'S)}

Two membranous regions of the nuclear envelope are not extracted by detergent in preparation of demembranated sperm nuclei for cell-free experiments (Fig. 5) although incubation in egg extracts eventually removes their lamin B and lamin-binding LBR proteins (Fig. 4). On the basis of their binding of lipophilic dyes and detergent resistance they were variously named lipophilic structures (LS's) or nuclear envelope remnants (NER's) (Collas and Poccia, 1995b; Byrne et al., 2007; Garnier-Lhomme, Byrne et al., 2009).

LS's appear to be "reinforced" or thickened layers of nuclear envelope (Fig. 6) and would resemble putative plasma membrane rafts in detergent insensitivity although their appearance is clearly different. They lie at two indentations of the conical sperm nucleus, at the tip and base, called the acrosomal and centriolar fossae and are incorporated directly into the forming male pronuclear envelope in vivo (Longo and Anderson, 1968). Using lipid mass spectrometry and deuterium solid-state NMR we found that they are relatively fluid membranes enriched in phosphoinositides, polyunsaturated phospholipids and cholesterol (Garnier-Lhomme, Dufourc, et al., 2009; Garnier-Lhomme, Byrne, et al., 2009). Depletion of their cholesterol interferes with nuclear envelope assembly in vitro.

Curiously, the sperm remnants are required for nuclear envelope precursor membrane vesicle binding to nuclei prior to fusion in the cell-free system (Collas and Poccia, 1995b). Binding is polarized, beginning in the regions of the LS's and proceeding towards the midline (Fig. 7). If LS's are removed with high concentrations of non-ionic detergents, egg membrane vesicles do not bind, but reconstitution of the LS's to the poles of the naked nuclei restores binding function. Upon addition of GTP, LS's fuse in the cell-free system with membrane vesicles derived from the egg extracts creating the male pronuclear membrane. Binding requires ATP but not ATP hydrolysis. Similar to other membrane fusion events, fusion requires $\mathrm{Ca}^{++}$and GTP hydrolysis. On the basis of these experiments, we suggested that LS's serve as nuclear envelope organizing structures. They are not species-specific. We demonstrated that similar detergent-resistant regions with similar locations and binding properties exist on sperm of other deuterostomes such as fish, frog, mouse and cattle (Collas and Poccia, 1996a). In those organisms (Fig. 8), LS's were always localized to centriolar fossa regions (where the sperm tail attaches) and acrosomal regions (which are not always located at the opposite extremity of the sperm head). Although binding of membrane vesicles was not species-specific, fusion was.

Therefore, LS's are conserved across the deuterostomes and may be used similarly in construction of male pronuclear or zygote nuclear envelopes in species other than the sea urchin. We suggested that specialized regions of nuclear envelope less apparent morphologically could also facilitate nuclear envelope formation following mitosis, a matter remaining to be investigated (Collas and Poccia, 1995b; Poccia and Collas, 1997). That LS's are apparent in sperm may be a consequence of the coalescence of similar regions of the haploid chromosome set during nuclear compaction occurring in spermatogenesis.
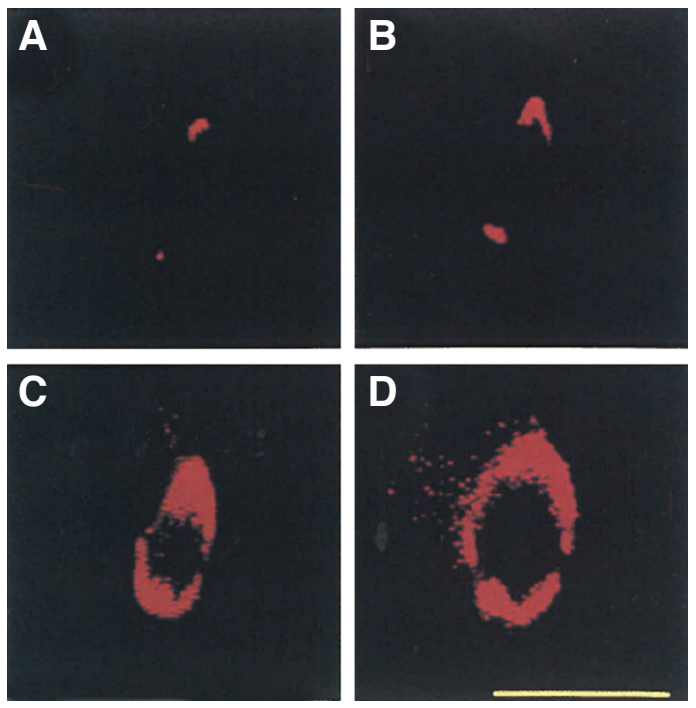

Fig. 7. Fluorescence image of polarized binding of egg membrane vesicles to sea urchin sperm nucleus in vitro. Sperm nuclei incubated in egg cytoplasmic extract containing ATP whose membrane vesicles were labeled red with DilC ${ }_{18}$ (A) $2 \mathrm{~min}$. (B) $10 \mathrm{~min}$. (C) $15 \mathrm{~min}$. (D) $20 \mathrm{~min}$. Bar, $5 \mu \mathrm{m}$. Binding begins in the regions of the lipophilic structures and spreads laterally. From Poccia and Collas (1997) 


\section{Egg membrane vesicle (MV) populations}

Typically the nuclear envelope forms largely from the endoplasmic reticulum. Fractionation of membrane vesicle populations from Xenopus egg extracts revealed roles for two sets of vesicles, only one of which was derived from the endoplasmic reticulum (Vigers and Lohka, 1991). This spurred us to attempt a fractionation of sea urchin egg cytoplasmic extracts (Collas and Poccia, 1996b).

Four fractions of MVs were isolated on sucrose density gradients (MV1-4). MV2 was further fractionated into MV2 $\alpha$ and MV2 $\beta$. The major MV2 $\beta$ fraction (75\% of total extract MVs) was enriched in an endoplasmic reticulum marker enzyme, MV2 $\alpha$ in a Golgi marker enzyme. They and MV1 bound to sperm nuclei in the cell-free system; the others did not. Binding was sensitive to protease, high salt and N-ethylmaleimide. MV1 and MV2 $\alpha$ bound to the LS regions of the nuclei; MV2 $\beta$ bound around the complete periphery. All three (and LS's) were required for complete nuclear
$10 \mathrm{~min}$
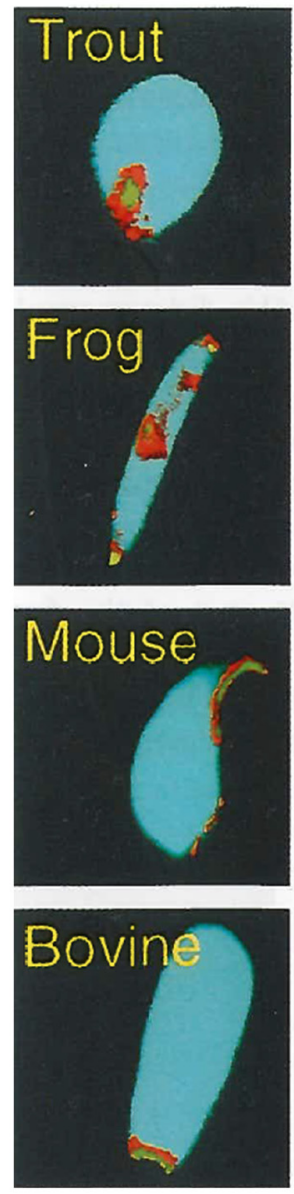

$30 \mathrm{~min}$
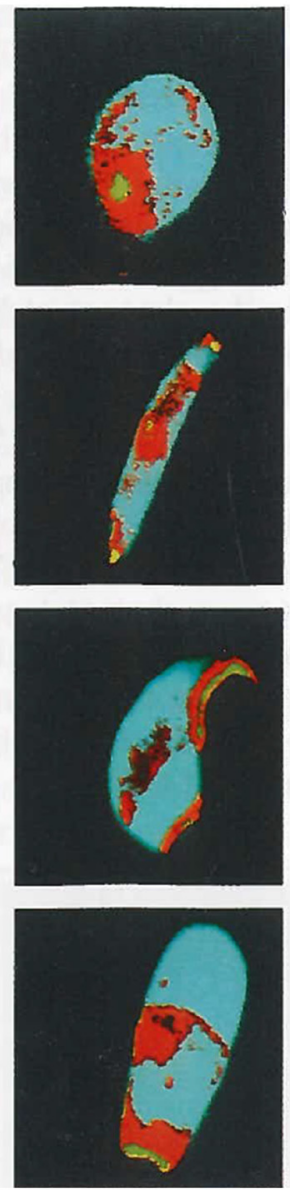

$60 \mathrm{~min}$
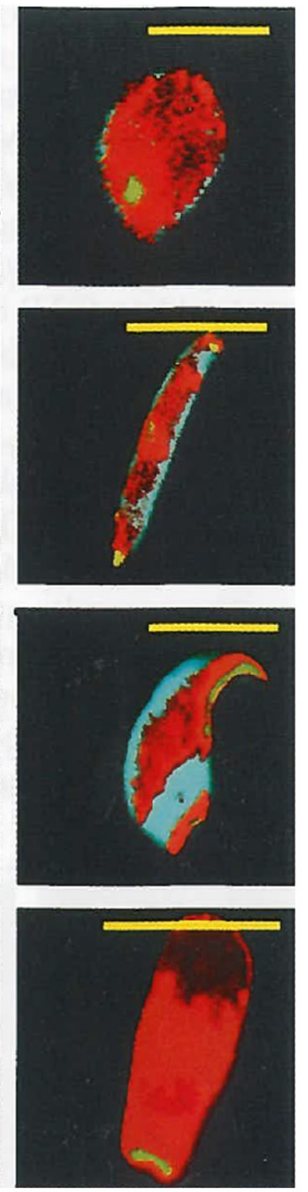

Fig. 8. Polarized binding of membrane vesicles to vertebrate sperm nuclei. Nuclei were demembranated in $0.1 \%$ Triton X-100 and LS's were fluorescently labeled green with diOC 6 . Sperm nuclei incubated in sea urchin egg cytoplasmic extracts containing ATP whose membrane vesicles were labeled red with DilC 18 . Vertebrate nuclei all show lipophilic regions at the centriolar fossa region where the axoneme is attached and a second region where the acrosome would have been located. Membrane vesicle binding to $L S$ regions is conserved between sea urchins and vertebrates. Bar, 5 um. From Collas and Poccia (1996a). envelope formation.

Therefore at least four different membrane populations contribute to nuclear membrane formation in vitro, three from the egg and one from the sperm. Quantitatively, the major contributor is the ER-derived fraction as expected.

\section{Egg lamins}

In addition to new inner and outer nuclear membranes, new lamina are necessary to complete the nuclear envelope. In the fertilized egg, a subset of MV2 $\beta$ was found to contain the lamin B receptor (LBR) which has domains that recognize lamins, chromatin and DNA and in mature sperm is found associated with the LS regions (Collas et al., 1996). LBR was necessary for MV2 $\beta$ binding to nuclei. A second subset of MV2 $\beta$ vesicles contained lamin $B$. None appeared to have both proteins. Lamin B incorporation into the in vitro-formed male pronuclei occurred only after the nuclei were enclosed in a nuclear membrane. Incorporated lamin B could originate from MV-bound or soluble forms. As mentioned above, formation of a lamina was necessary for nuclear swelling beyond the initial $4 \mu \mathrm{m}$ diameter decondensed structure.

The MV2 $\beta$ fraction is dynamic. Using immunoprecipitation and sucrose gradient fractionation we showed that lamin B and LBR coexist in vesicles in unfertilized egg cytoplasm but do not interact. However, by 12 min following fertilization, after ER vesiculation and nuclear membrane reformation, the proteins are segregated to different vesicles remaining this way throughout the DNA synthesis phase (Collas et al., 2000). During mitosis a small proportion, possibly derived from nuclear envelope breakdown, can be detected with co-localized lamin B and LBR in vesicles.

Thus, LBR appears to direct binding of ER-derived membranes to the chromatin to assemble a new nuclear envelope which then imports lamin B which binds to LBR and forms a lamina. The functional new envelope can then import proteins and nuclei can swell with addition of new membrane and incorporation of proteins.

\section{A role for phosphoinositides in MV fusion and NE for- mation}

Another unexpected feature of MVs was discovered when methods were established to determine their phospholipid contents. We developed a sensitive 2-dimensional heteronuclear multiple quantum coherence NMR spectroscopy procedure to assign the main classes of phospholipids to MV fractions using ${ }^{31} \mathrm{P}$ and ${ }^{1} \mathrm{H}$ (Larijani et al., 2000). Although the major ER-derived fraction MV2 and the MV3 fraction were rather typical in composition (mostly phosphatidylcholine and phosphatidylethanolamine with lesser amounts of phosphatidylserine and phosphatidylinositides), MV1 contained predominantly phosphatidylinositides (Ptdlns) with small amounts of phosphatidylcholine.

This highly unusual composition suggested that Ptdlns metabolism played a role in the special function of MV1. A later analysis by liquid chromatography-electrospray ionization tandem mass spectrometry (Fig. 9) showed that MV1 contained 60\% phosphoinositides (2/3 of which were phosphorylated derivatives) and had 25-times as much Ptdlns $(4,5) \mathrm{P}_{2}$, the substrate for PI-PLC, as did MV2, the composition of which resembled more typical membranes (Byrne et al., 2007). Furthermore, compared to MV2, MV1 was much more enriched in diacyl species of Ptdlns $(4,5) \mathrm{P}_{2}$ which are used preferentially by PI-PLC. Since PLC $\gamma$ was found to be $>100$-fold 
enriched in MV1, this suggested that MV1 could serve as a rich localized source of the fusigenic lipid diacylglycerol.

\section{Polarity of membrane fusion}

Direct demonstration of the polarity of egg vesicle binding to sperm chromatin (Collas and Poccia, 1995b) was extended to the polarity of fusion which also begins in the LS regions (Dumas et al., 2010). In order to test if fusion was polarized, several technical tricks were employed. Membrane vesicles were labelled separately with either BODIPY-C ${ }_{12}$ or DilC ${ }_{12}$, two fluorescent lipophilic dyes that interact by Förster Resonance Energy Transfer (FRET). In FRET, an appropriate donor-acceptor pair of molecules is selected so that excitation of the donor results in non-radiative dipole-dipole coupling transfer of energy to the acceptor which then fluoresces as though directly irradiated. Since FRET interactions occur only over very short distances $(<10 \mathrm{~nm})$, if the two molecules reside in separate vesicles they cannot interact but if they come to reside in the same fluid membrane following fusion they can.

To inhibit movement, small sperm nuclei were immobilized in a transparent, permeable agarose gel which contained a caged form of GTP. Upon its uncaging with UV light, GTP hydrolysis initiated the fusion reaction which was imaged by FLIM-FRET as a decrease in average lifetime of the donor. The LS's of the sperm nuclei were independently labeled with a fluorescent compound to provide orientation.

Upon initiation of the reaction, FRET interactions and thus the kinetics of fusion were observed to proceed from the two poles towards the equator (Fig. 10). Thus fusion of MV2 vesicles on the sperm chromatin surface began in the regions of the LS's that bind $\mathrm{MV} 1$ vesicles and was propagated laterally. This led to a model in which preferential binding of MV1 to the LS regions led, following GTP hydrolysis, to local high levels of the fusigenic lipid diacylglycerol (DAG) within MV1 which facilitated its fusion with adjacent $M V 2$ vesicles. The fused regions then facilitated successive fusions of more MV2 vesicles either by using the initially generated DAG or subsequent enrichment until the nuclear envelope was completed.

\section{Signaling pathway of DAG: localized fusigen formation}

The unique role of MV1 and its potential in signal transduction leading from GTP hydrolysis to membrane fusion were investigated in several studies using the cell-free system. In vitro a bacterial phosphatidylinositide-specific phospholipase C (PI-PLC) mimicked GTP hydrolysis as an inducer of nuclear envelope formation suggesting that hydrolysis of $\operatorname{Ptdlns}(4,5) \mathrm{P}_{2}$ might be downstream of GTP hydrolysis (Larijani et al., 2001).

Endogenous PLC induction depends on the presence of MV1. Additionally, two inhibitors of Ptd Ins-3 kinase blocked GTP induced $\mathrm{NE}$ formation, consistent with an additional role for Ptdlns moieties phosphorylated in the 3-position. Since the bacterial enzyme does not produce inositol triphosphate which normally leads to $\left[\mathrm{Ca}^{++}\right]$ elevation, we postulated that the local production of the other hydrolysis product of the reaction, fusigenic diacylglycerol (DAG), promoted nuclear membrane precursor fusion.

Consistent with this hypothesis, we showed that liposomes or large unilammellar vesicles (LUVs) containing Ptdlns $(4,5) \mathrm{P}_{2}$ were able to substitute for MV1 in the cell-free system promoting nuclear envelope formation when GTP was added (Barona et al., 2005). In

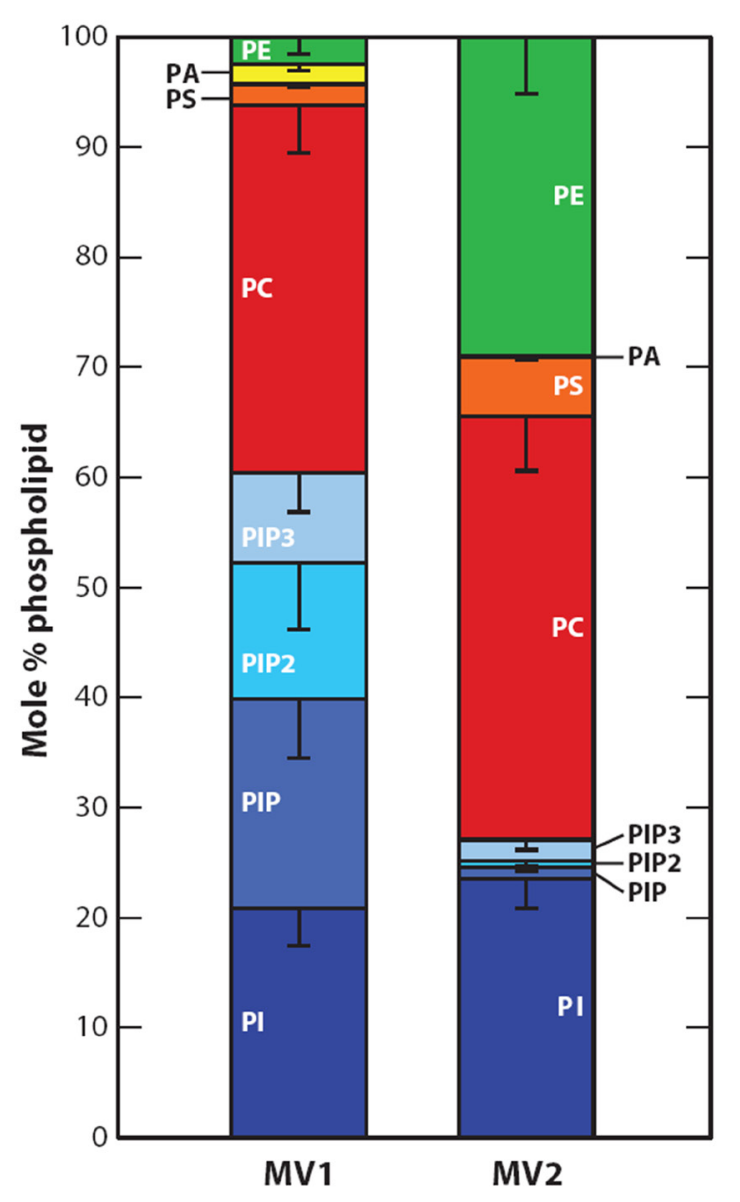

Fig 9. Phospholipid composition of egg membrane vesicle fractions MV1 and MV2. Determined by electrospray ionization tandem mass spectrometry. Pl, phosphatidylinositol; PIP, phosphatidylinositol phosphate; PIP2, phosphatidylinositol bisphosphate; PIP3, phosphatidylinositol trisphosphate, $P C$, phosphatidylcholine; PS, phosphatidylserine; PA, phosphatidic acid; $P E$, phosphatidylethanolamine. From Larijani and Poccia (2009).

addition, if the LUVs were pre-hydrolyzed with PI-PLC they initiated NE formation spontaneously as did LUVs enriched in DAG. NE formation was also blocked by two inhibitors of the endogenous PI-PLC (Byrne et al., 2005; Larijani et al., 2001).

During NE formation in the cell-free system, PLC $\gamma$ is transiently phosphorylated on the Tyr 783 position indicative of PLC activation following GTP hydrolysis (Byrne et al., 2007; Larijani and Poccia, 2007). The MV1 vesicles containing PLC $\gamma$ and its substrate Ptdlns $(4,5) \mathrm{P}_{2}$ are associated with the male pronuclei prior to $\mathrm{NE}$ formation. PLC $\gamma$ is phosphorylated by a member of the src-family of tyrosine kinases, SFK1 (Byrne et al., 2009; Byrne et al., 2009). A model was proposed in which GTP hydrolysis led to activation of SFK1 which directly phosphorylated and activated PLC $\gamma$ leading to localized production of the fusigenic DAG and membrane fusion (Larijani and Poccia, 2009).

The direct interaction of the two proteins was subsequently revealed through the use of protein FRET-FLIM techniques. SFK1 and PLC $\gamma$ were co-recruited to sperm nuclei in vivo and shown to directly interact during early stages of male pronuclear envelope formation (Byrne et al., 2012). In addition in vivo phosphorylation of PLC $\gamma$ on Tyr-783 within minutes of fertilization was demonstrated by 

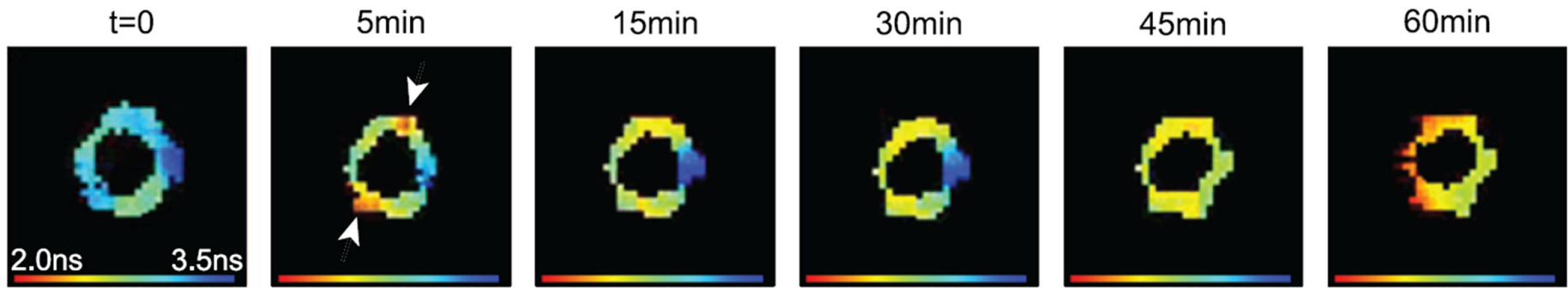

Fig. 10. Polarized fusion of MVs on surface of male pronuclei revealed by FRET-FLIM begins in LS regions. Egg extract membranes were independently labelled with either BODIPY $C_{12}$ (donor) or dil $C_{12}$ (acceptor) and mixed together. Sperm nuclei and ATP were added. LS's of the nuclei were pre-labelled with hydroxycoumarin to mark their positions (white arrowheads). Nuclei with bound MVs were placed in cytosol with caged GTP and embedded in low melting agarose to immobilize them. Membranes were visualized by two-photon fluorescence microscopy. Fluorescence lifetime of BODIPY was measured before $(t=0)$ and after $(t=5,15,30,45$ and 60 minutes) the induction of NE formation by photo activation of caged-GTP. Decrease in fluorescence lifetime of donor indicates regions of dye mixing in same membrane (fusion). From Dumas et al., (2010).

immunofluorescence techniques. The interaction between the two enzymes declines in vitro after GTP is added as phosphorylation of PLC $\gamma$ is transiently detected (Fig. 11). The transient phosphorylation and NE formation required both GTP hydrolysis and SFK activity.

Thus a refined model was presented in which, following sperm chromatin decondensation, MV1 binds to the LS regions and MV2 $\beta$ binds from poles to equator. PLC $\gamma$ and SFK interact but
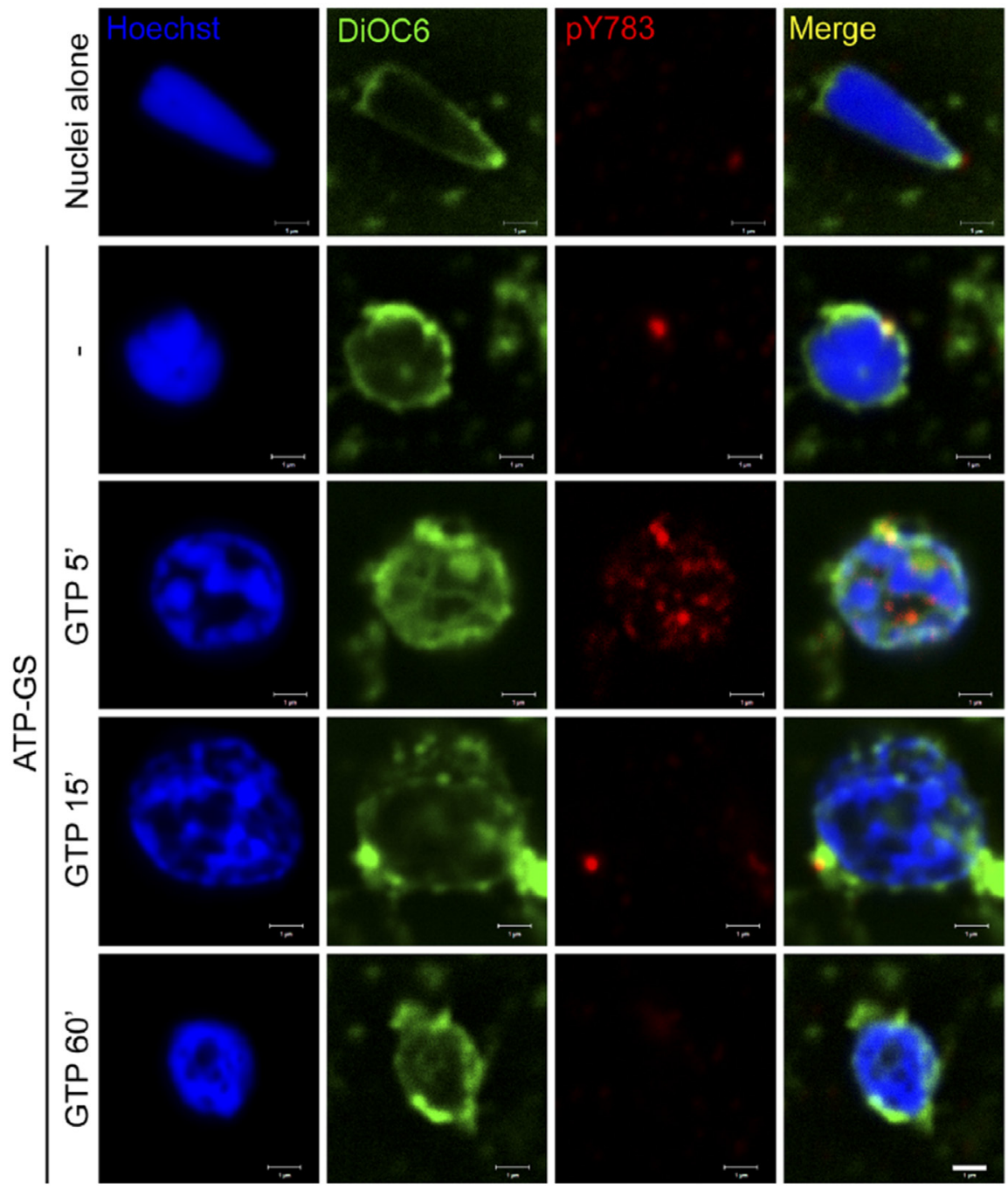

PLC $\gamma$ is prevented from immediate activation by an inhibitor of SFK (possibly the non-receptor tyrosine kinase, Csk) until GTP hydrolysis removes the inhibition. SFK1 then phosphorylates and activates PLC $\gamma$ which hydrolyzes PtdlnsP $(4,5) \mathrm{P}_{2}$ in the LS's to produce elevated levels of DAG, facilitating fusion with MV2 $\beta$. SFK1 and the now activated PLC $\gamma$ dissociate and the DAG signal is propagated laterally with successive fusions of MV2 $\beta$ until the NE is completed (Fig. 12). A similar mechanism appears to operate in the subsequent fusion of male and female pronuclear envelopes (Byrne et al., 2014).

The signaling pathway leading to localized formation of DAG following GTP hydrolysis is not completely known. The endogenous GTPase responsible for initiation has not been identified and various levels of regulation including roles of Ptdlns-3 kinase need further elucidation. Identification of some of the major players and their changing interactions however provide a plausible model for the regulation of the initiation of membrane fusion leading to nuclear envelope formation.

\section{A role for lipids exhibiting intrinsic nega- tive curvature in membrane fusion and organelle shape}

Although DAG is a second messenger involved in many signaling pathways in most cells, we interpreted its effects on fusion to be due to its physical properties. Fusigenic DAG possesses intrinsic negative curvature. Such lipids have conical shapes because of their small head groups and larger hydrophobic tails that cause a

Fig. 11.Transient phosphorylation of PLC $\gamma$ onTyr783 on the NE in vitro. Demembranated sperm nucle were fixed alone (top row) or decondensed in fertilized egg cytoplasmic extract with ATP and GTP for the times indicated. They were then fixed and stained with Hoechst 33342 (blue), DiOC 6 (green) and anti-pY783 of $P L C \gamma$ (red) and imaged by confocal microscopy. Scale Bar, 1 um. From Byrne et al., (2012). 
A

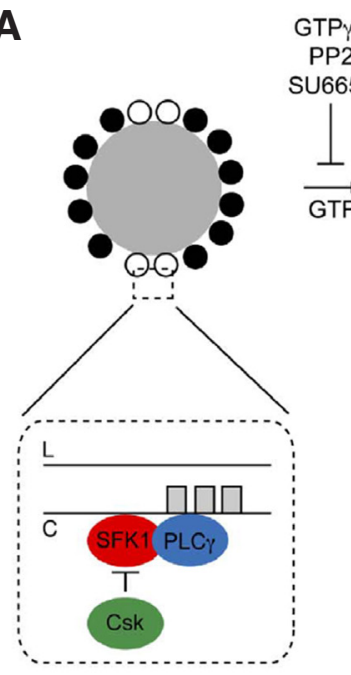

B PP2 SU6656 $\underset{\mathrm{GTP}}{\stackrel{\perp}{\perp}}$

MV1

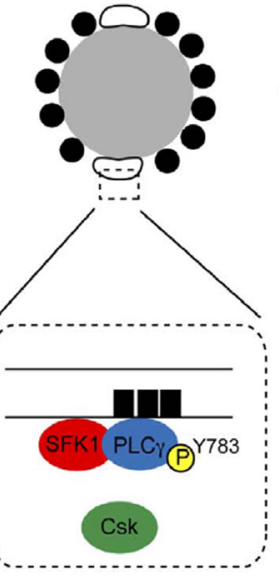

C
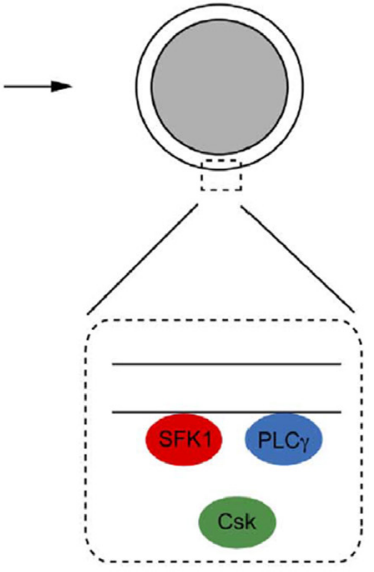

Fig. 12. Model of molecular events leading to nuclear envelope (NE) formation in vitro. Decondensed sperm nuclei bind egg membranes including MV1 and ER-derived MV2. (A) MV1 vesicles enriched in SFK1, PLC $\gamma$ and Ptdlns (4,5) $P_{2}$ bind near the two sperm LS's. SFK1 and PLCy directly interact. The premature phosphorylation of PLCy by SFK1 is prevented by putative CSK inhibition of SFK1. (CSK tyrosine protein kinases typically phosphorylate Src family proteins to inhibit them.) (B) Upon addition of GTP, CSK inhibition of SFK 1 is removed, and SFK 1 phosphorylates PLCY on its Tyr783 residue, a pre-requisite for full PLCy activation. Once active, $P L C \gamma$ hydrolyses Ptdlns $(4,5) P_{2}$ to the fusigenic lipid DAG, which initially promotes membrane fusion events between $M V 1$ vesicles and LS's. (C) Fusion of MV2 sequentially spreads over the surface of the sperm nucleus until it is enclosed by a continuous double bilayer eventually perforated with nuclear pore complexes. After fusion is initiated, PLCY and SFK1 dissociate but remain on the nuclear envelope. $L$ and $C$ denote the luminal and cytoplasmic faces of vesicles respectively. ER denotes endoplasmic reticulum-derived membranes. From Byrne et al., (2012).

monolayer to bend towards the head group. Their shape facilitates bilayer bending by filling in the hydrophobic gaps that are created in regions of bending, making them more energetically favorable (Kozlovsky and Kozlov, 2002). Extreme bending is a property of the stalks postulated to be transient fusion intermediates. An important additional property of DAG is its tendency to promote non-lamellar phases in membranes, such as inverted hexagonal and cubic phases, which may also form during fusion (Goñi, 2014). Vesicles with 5-40\% DAG have been shown to readily fuse in vitro (Villar et al., 2001).

More stable examples of extreme membrane curvature occur in certain organelles such as tubules of the endoplasmic reticulum, sheet edges of Golgi stacks and small vesicles. Changes or maintenance of curvature and control of fusion in vivo are usually attributed to proteins, but an important role for lipids cannot be dismissed. Both are likely to contribute to organelle shape

Because the gold standard for cell-free systems is comparison to in vivo phenomena, we modified the DAG composition of membranes in living mammalian cells and sea urchin oocytes to observe effects on nuclear envelope formation (Domart et al., 2012). Transfection of HeLa or COS cells allowed us to acutely induce DAG depletion in the endoplasmic reticulum and nuclear envelope precursor membranes of mitotic cells. Depletion resulted in failure of telophase nuclear envelope formation and unexpectedly in formation of multi-lamellar sheets of endoplasmic reticulum. In the sea urchin, karyomere fusion was inhibited (karyomeres are individual chromosomes surrounded by nuclear envelopes that fuse with one another to reconstitute diploid nuclei) and again endoplasmic reticulum membranes were aberrant, displaying an increase of sheets at the expense of tubules.

The relationship between nuclear membrane fusion failure and ER sheet accumulation when DAG is depleted can be rationalized by a similar requirement for negative curvature lipids. Therefore alterations of the proportions of sheets or tubules in the continuous ER structure would be predicted to depend on overall negative curvature lipid composition.
The effects of alteration of negative curvature lipid content in the oocytes were documented in experiments in which DAG was lowered in unfertilized eggs by microinjection of DAG kinase to convert DAG to phosphatidic acid or of Syn 1, a phosphatase which depletes the metabolic precursor of diacylglycerol, Ptdlns $(4,5) \mathrm{P}_{2}$. In both cases, tubules were converted to sheets. This effect was attenuated by supplementing oocyte lipids with a non-signaling isomer of DAG (1,3 DAG) that displays negative curvature prior to enzyme injection (Wang et al., 2013; Larijani et al., 2014). Unrelated phospholipids of negative curvature behaved similarly but the cylindrical lipid phosphatidylcholine did not.

These experiments suggest that phospholipids play structural roles in cell membranes that have important consequences for their functions in live cells and confirmed the utility of in vitro investigations of membrane biochemistry to suggest testable in vivo mechanisms. They demonstrated that proteins alone are an insufficient explanation for control of fusion or maintenance of organelle shape.

\section{Conclusion}

The development of a cell-free system from sea urchin eggs has allowed us to investigate the earliest steps in formation of the male pronucleus that follow fertilization. It supplements the much more extensively studied cell-free system from frog eggs and added several new and unexpected discoveries to the mechanisms of chromatin decondensation, histone modification, polarized initiation of nuclear envelope formation, multiple roles of phosphoinositide modification in promoting membrane fusion, and the role of lipid of intrinsic negative curvature in bending and fusion of biological membranes of the nuclear envelope and endoplasmic reticulum.

\section{Acknowledgement}

Many students and collaborators have contributed to this work over the years. I am most indebted to four graduate/post-doctoral students and collaborators for major advances: Drs. Ray Green, Philippe Collas, Richard 
Byrne and Banafshé Larijani and several undergraduates, especially Lisa Cameron, Marcia Simpson, Scott Stephens, Aupola Kundu, Burr Fong, Fadi Hamati, Gabriela Ulloa and Alan Wang for substantial contributions to the studies described here.

\section{References}

BARONA T, BYRNE RD, PETTITT R, WAKELAM MJO, LARIJANI B, POCCIA D (2005). Diacylglycerol induces fusion of nuclear envelope membrane precursor vesicles, J Biol Chem 280: 41171-41177.

BYRNE RD, BARONA TM, GARNIER M, KOSTER G, KATAN M, POCCIA DL, LARIJANIB (2005). Nuclear envelope assembly is promoted by phosphoinositidespecific phospholipase $\mathrm{C}$ with selective recruitment of phosphatidylinositol-enriched membranes. Biochem J 387: 393-400.

BYRNE RD, GARNIER-LHOMME M, HAN K, DOWICKI M, MICHAEL N, TOTTY N, ZHENDRE V, CHO A, PETTITT TR, WAKELAM MJ, POCCIA DL, LARIJANI B (2007). PLC $\gamma$ is enriched on poly-phosphoinositide-rich vesicles to control nuclear envelope assembly. Cell Signal 19: 913-922.

BYRNE RD, LARIJANI B, POCCIA DL (2009). Tyrosine kinase regulation of nuclear envelope assembly. Adv Enz Regul 49: 148-156.

BYRNE RD, POCCIA DL, LARIJANI B (2009). Role of phospholipase C in nuclear envelope assembly. Clin Lipidol 4: 103-112.

BYRNE RD, ZHENDRE V, LARIJANI B, POCCIA DL (2009). Nuclear envelope formation in vitro: a sea urchin egg cell-free system. Meth Mol Biol 464: 207-223.

BYRNE RD, APPLEBEE C, POCCIA DL, LARIJANI B (2012). Dynamics of PLC $\gamma$ and Src Family Kinase 1 Interactions during Nuclear Envelope Formation Revealed by FRET-FLIM. PLoS One 7: e40669.

BYRNE RD, VEERIAH S, APPLEBEE CJ, LARIJANI B (2014). Conservation of proteo-lipid nuclear membrane fusion machinery during early embryogenesis Nucleus 5: 441-448.

CAMERON LA, POCCIA DL (1994). In vitro development of the sea urchin male pronucleus. Dev Biol 162: 568-578.

COHEN H., NEWROCK,K.,M., L, ZWEIDLER A (1975). Stage specific switches in histone synthesis during embryogenesis of the sea urchin. Science 190: 994-997.

COLLAS P, POCCIA D (1995a). Formation of the sea urchin male pronucleus in vitro: Membrane-independent chromatin decondensation and nuclear-envelope dependent nuclear swelling. Molec Reprod Dev 42: 106-113.

COLLAS P, POCCIA D (1995b). Lipophilic organizing structures of sperm nuclei target membrane vesicle binding and are incorporated into the nuclear envelope. Dev Biol 169: 123-135.

COLLAS P, POCCIA D (1996a). Conserved binding recognition elements of sperm chromatin, sperm lipophilic structures and nuclear envelope precursor vesicles. Eur J Cell Biol 71: 22-32.

COLLAS P, POCCIA D (1996b). Distinct egg cytoplasmic membrane vesicles differing in binding and fusion properties contribute to sea urchin male pronuclear envelopes formed in vitro. J Cell Sci 109: 1275-1283.

COLLAS P, COURVALIN J-C, POCCIA D (1996). Targeting of membranes to sea urchin sperm chromatin is mediated by an LBR-like integral membrane protein. $J$ Cell Biol 135: 1715-1725.

COLLAS P, THOMPSON L, FIELDS A, POCCIA DL, COURVALIN JC (1997). Protein kinase C-mediated interphase lamin B phosphorylation and solubilization. J Biol Chem 272: 21274-21280.

COLLAS P, POCCIA D (1998a). Methods for studying in vitro assembly of male pronuclei using extracts from marine invertebrates: sea urchins and surf clams. Meth Cell Biol 53: 417-452.

COLLASP, POCCIAD (1998b). Remodeling the sperm nucleus into a male pronucleus at fertilization. Theriogenology 49: 67-81.

COLLAS P, POCCIA D (2000). Membrane fusion events during nuclear envelope assembly. Subcell Biochem 34: 273-302.

COLLAS P, BARONA T, POCCIA DL (2000). Rearrangements of sea urchin egg cytoplasmic membrane domains at fertilization. Eur J Cell Biol 79: 10-16.

COTHREN CC, POCCIA DL (1993). Two steps required for male pronucleus formation in the sea urchin egg. Exp Cell Res 205: 126-133.

DOMARTM-C, HOBDAYTMC, PEDDIE CJ, CHUNG GHC, WANGA, YEHK, JETHWA
$N$, ZHANG Q, WAKELAM MJO, WOSCHOLSKIR, BYRNE RD, COLLINSON LM, POCCIA DL, LARIJANI B (2012). Acute manipulation of diacylglycerol reveals roles in nuclear envelope assembly \& endoplasmic reticulum morphology. PLOS One 7: e51150.

DUMAS F, BYRNE RD, VINCENT B, HOBDAY TMC, POCCIA DL, LARIJANI B (2010). Spatial regulation of membrane fusion controlled by modification of phosphoinositides PLOS One 5: e12208.

GANDINI ATTARDI D, MARTINI G, MATTOCCIA E, TOCCHINI-VALENTINI GP (1976). Effect of Xenopus laevis oocyte extract on supercoiled simian virus 40 DNA: formation of complex DNA. Proc Natl Acad Sci USA 73: 554-558.

GARNIER-LHOMME M, BYRNE RD, HOBDAY TMC, GSCHMEISSNER S, WOSCHOLSKI R, POCCIA DL, DUFOURC EJ, LARIJANI B (2009). Nuclear envelope remnants: fluid membranes enriched in sterols and polyphosphoinositides. PLOS One 4: e4255.

GARNIER-LHOMME M, DUFOURC EJ, LARIJANI B, POCCIAD (2009). Lipid quantification and structure determination of nuclear envelope precursor membranes in the sea urchin. Methods Mol Biol 462: 89-110.

GOÑI FM (2014). The basic structure and dynamics of cell membranes: an update of the Singer-Nicolson model. Biochim Biophys Acta 1838: 1467-1476.

GREEN GR, POCCIA DL (1985). Phosphorylation of sea urchin sperm H1 and H2B histones precedes chromatin decondensation and $\mathrm{H} 1$ exchange during pronuclear formation. Dev Biol 108: 235-245.

GREEN GR, POCCIADL (1988). Interaction of sperm histone variants and linker DNA during spermiogenesis in the sea urchin. Biochemistry 27: 619-625.

GREEN GR, LEE H-JJ, POCCIADL (1993). Phosphorylation weakens DNA binding by peptides containing multiple "SPKK" sequences. J Biol Chem 268: 11247-11255.

GREEN GR, BALHORNR, POCCIADL, HECHTNB (1994). Synthesis and processing of mammalian protamines and transition proteins. Molec Reprod Dev37:255-263.

GREEN GR, COLLAS P, BURRELL A, POCCIA DL (1995). Histone phosphorylation during sea urchin development. Semin Cell Biol 6: 219-227.

HILL CS, THOMAS JO (1990). Core histone-DNA interactions in sea urchin sperm chromatin. The N-terminal tail of H2B interacts with linker DNA. Eur $J$ Biochem 187: 145-153.

HILL CS, RIMMER JM, GREEN BN, FINCH JT, THOMAS JO (1991). Histone-DNA interactions and their modulation by phosphorylation of-Ser-Pro-X-Lys/Arg-motifs. EMBO J 10: 1939-1948.

KOZLOVSKY Y, KOZLOV MM (2002). Stalk Model of Membrane Fusion : Solution of energy crisis. Biophys $J$ 82: 882-895.

LARIJANI B, POCCIA DL, DICKINSON LC (2000). Phospholipid identification and quantification of membrane vesicle subfractions by two-dimensional $31 \mathrm{P}-1 \mathrm{H}$ nuclear magnetic resonance. Lipids 35: 1289-1297.

LARIJANI B, BARONA TM, POCCIA DL (2001). Role for phosphatidylinositol in nuclear envelope formation. Biochem J 356: 495-501.

LARIJANI B, POCCIA D (2007). Protein and lipid signaling in membrane fusion: nuclear envelope assembly. Signal Transduct 7: 142-153.

LARIJANI B, POCCIA D (2009). Nuclear envelope formation: mind the gaps. Annu Rev Biophys 38: 107-124.

LARIJANI B, POCCIAD (2012). Effects of phosphoinositides and their derivatives on membrane morphology and function. Curr Top Microbiol Immunol 362: 99-110.

LARIJANI B, HAMATI F, KUNDU A, CHUNG GC, DOMART M-C, COLLINSON L, POCCIA DL (2014). Principle of duality in phospholipids: regulators of membrane morphology and dynamics. Biochem Soc Trans 42: 1335-1342.

LOHKA M, MASUI Y (1983a). Formation in vitro of sperm pronuclei and mitotic chromosomes induced by amphibian ooplasmic components. Science 220: 719-721.

LOHKA M, MASUI Y (1983b). The germinal vesicle material required for sperm pronuclear formation is located in the soluble fraction of egg cytoplasm. Exp Cell Res 148: 481-491.

LOHKA M, MASUI Y (1984a). Effects of $\mathrm{Ca}^{++}$ions on the formation of metaphase chromosomes and sperm pronuclei in cell-free preparations from unactivated Rana pipiens eggs. Dev Biol 103: 434-442.

LOHKA M, MASUI Y (1984b). Roles of cytosol and cytoplasmic particles in nuclear envelope assembly and sperm pronuclear formation in cell-free preparations from amphibian eggs. J Cell Biol 98: 1222-1230.

LONGO FJ, ANDERSON E (1968). The fine structure of pronuclear development and fusion in the sea urchin, Arbacia punctulata. J Cell Biol 39: 339-368. 
LUTTMER SJ, LONGO FJ (1987). Rates of male pronuclear enlargement in sea urchin zygotes. J Exp Zool 243: 289-298.

MATTOCCIA E, ATTARDI DG, TOCCHINI-VALENTINI GP (1976). DNA-relaxing activity and endonuclease activity in Xenopus laevis oocytes. Proc Natl Acad Sci USA 73: 4551-4554.

NAKAI M, ITO J, KASHIWAZAKI N, MEN NT, TANIHARA F, NOGUCHI J, KANEKO $\mathrm{H}$, ONISHI A, KIKUCHI K (2015). Treatment with protein kinase $\mathrm{C}$ activator is effective for improvement of male pronucleus formation and further embryonic development of sperm-injected oocytes in pigs. Theriogenology 85: 703-708.

OLIVAR, DIXON GH (1991). Vertebrate protamine genes and the histone-to-protamine replacement reaction. Prog Nucl Acid Res Molec Biol 40: 25-94.

OLIVER MI, CONCHA C, GUTIÉRREZ S, BUSTOS A, MONTECINO M, PUCHI M, IMSCHENETZKY M (2002). Remodeling of sperm chromatin after fertilization involves nucleosomes formed by sperm histones $\mathrm{H} 2 \mathrm{~A}$ and $\mathrm{H} 2 \mathrm{~B}$ and two CS histone variants. J Cell Biochem 85: 851-859.

POCCIA D, KRYSTAL G, NISHIOKA D, SALIK J (1978). Control of sperm chromatin structure by egg cytoplasm in the sea urchin. In ICN-UCLA Symp Molec Cell Biol Cell Reprod Chap 17 Acad Press pp. 197-206.

POCCIA DL, GREENOUGH T, GREEN GR, NASH E, ERICKSON J, GIBBS M (1984). Remodeling of sperm chromatin following fertilization: Nucleosome repeat length and histone variant transitions in the absence of DNA synthesis. Dev Biol 104: 274-286.

POCCIAD (1986). Remodeling of nucleoproteins during gametogenesis, fertilization, and early development. Int Rev Cytol 105: 1-65.

POCCIA D, GREEN GR (1986). Nuclei and chromosomal proteins. Meth Cell Biol 27: $153-173$

POCCIA DL, SIMPSON M V, GREEN GR (1987). Transitions in histone variants during sea urchin spermatogenesis. Dev Biol 121: 445-453.

POCCIA DL (1989). Reactivation and remodeling of the sperm nucleus following fertilization. In "The Molecular Biology of Fertilization" (Ed. G Schatten, H Schatten) Chap 6. Acad Press, pp. 115-135.
POCCIA D, PAVAN W, GREEN GR (1990). 6DMAP inhibits chromatin decondensation but not sperm histone kinase in sea urchin male pronuclei. Exp Cell Res 188: 226-234.

POCCIADL, GREEN GR (1992). Packaging and unpackaging the sea urchin genome. Trends Biochem Sci 17: 223-227.

POCCIA D, COLLAS P (1996). Transforming sperm nuclei into male pronuclei in vivo and in vitro. Curr Top Devel Biol 34: 25-88.

POCCIA D, COLLAS P (1997). Nuclear envelope dynamics during male pronuclear development. Devel Growth Differ 39: 541-550.

POCCIAD, BARONAT, COLLAS P, LARIJANI B (2002). Nuclear envelope assembly in gametes and pronuclei. In Dynamics of Nuclear Assembly in Embryos and Somatic Cells (Ed. P Collas) Chap. 11 Klewer/Plenum pp. 111-130.

ROBERGE TH'NG,J., HAMAGUCHI,J. M, BRADBURYEM (1990). The topoisomerase II inhibitor VM-26 induces marked changes in histone $\mathrm{H} 1$ kinase activity, histones $\mathrm{H} 1$ and $\mathrm{H} 3$ phosphorylation and chromosome condensation in $\mathrm{G} 2$ phase mitotic BHK cells. J Cell Biol 111: 1753-1762.

SAVIC A, RICHMAN P, WILLIAMSON P, POCCIA D (1981). Alterations in chromatin structure during early sea urchin embryogenesis. Proc Natl Acad Sci USA 78 3706-3710.

SIMPSON M V, POCCIA D (1987). Sea urchin testicular cells evaluated by fluorescence microscopy of unfixed tissue. Gamete Res 17: 131-144.

STEPHENS S, BEYER B, BALTHAZAR-STABLEIN U, DUNCAN R, KOSTACOS M, LUKOMA M, GREEN GR, POCCIA D (2002). Two kinase activities are sufficient for sea urchin sperm chromatin decondensation in vitro. Molec Reprod Dev 62: 496-503.

VIGERS GPA, LOHKAMJ (1991). Adistinct vesicle population targets membranes and pore complexes to the nuclear envelope in Xenopuseggs. J Cell Biol112:545-556.

VILLAR A V, GONI FM, ALONSO A (2001). Diacylglycerol effects on phosphatidylinositol-specific phospholipase C activity and vesicle fusion. FEBS Lett 494: 117-120.

WANG A, KUNDU A, FONG B, FITZGERALD J, POCCIA D (2013). A structural role for lipids in organelle shaping. Biol Bull 224: 218-226. 
Further Related Reading, published previously in the Int. J. Dev. Biol.

Control of timing of embryonic M-phase entry and exit is differentially sensitive to CDK1 and PP2A balance

Mohammed El Dika, Damian Dudka, Claude Prigent, Jean-Pierre Tassan, Malgorzata Kloc and Jacek Z. Kubiak

Int. J. Dev. Biol. (2014) 58: 767-774

Nuclear reprogramming in zygotes

Chanchao Lorthongpanich, Davor Solter and Chin Yan Lim

Int. J. Dev. Biol. (2010) 54: 1631-1640

Cyclin B2/cyclin-dependent kinase1 dissociation precedes CDK1 Thr-161 dephosphorylation upon M-phase promoting factor inactivation in Xenopus laevis cell-free extract Franck Chesnel, Franck Bazile, Aude Pascal and Jacek Z. Kubiak Int. J. Dev. Biol. (2007) 51: 297-305

Remodeling of sperm chromatin induced in egg extracts of amphibians.

C Katagiri and K Ohsumi

Int. J. Dev. Biol. (1994) 38: 209-216
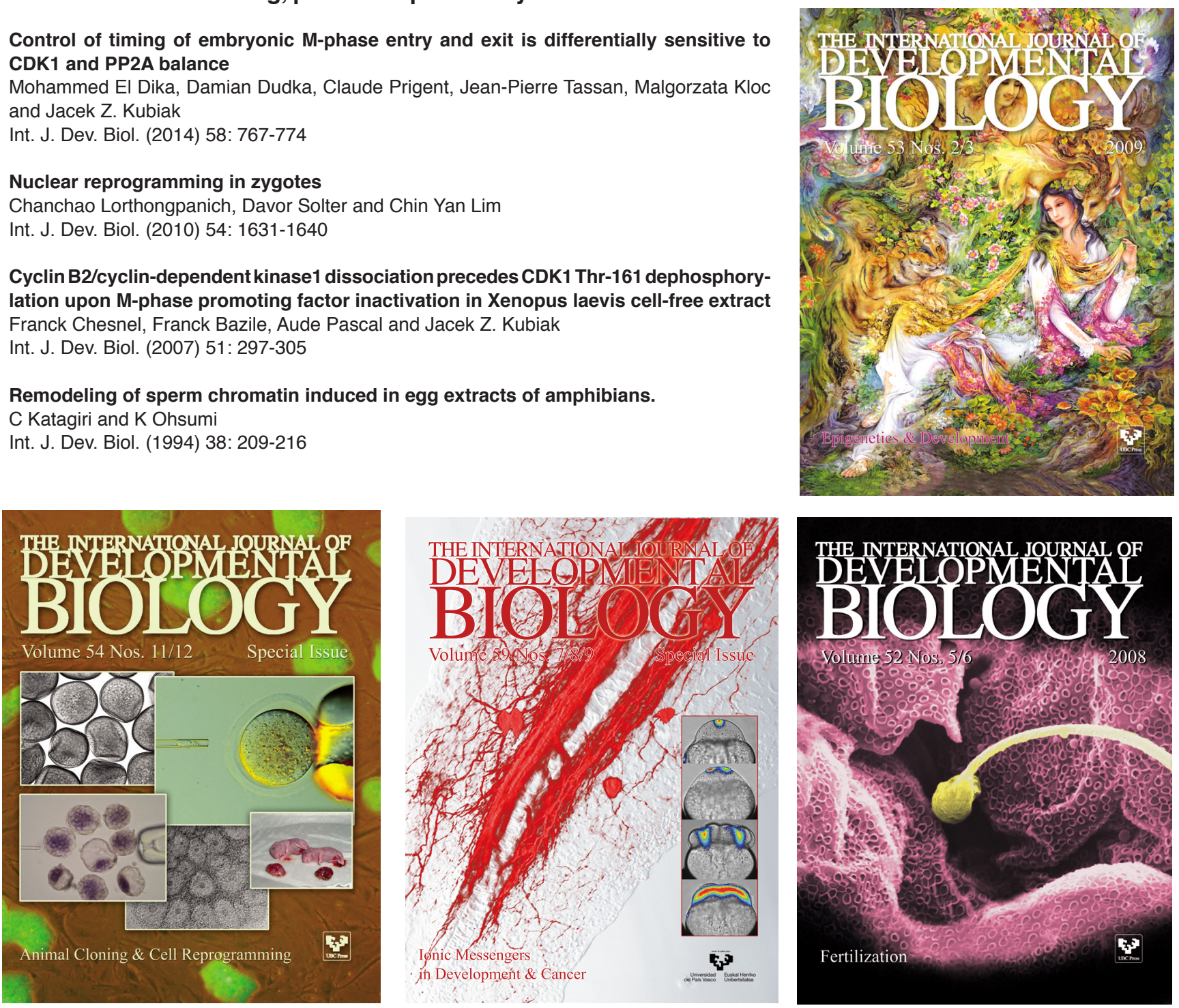